\title{
Spatial Approach to Contribution of Public Policies to the Dynamization of the Rural Population
}

\author{
Oscar Luis Alonso Cienfuegos ${ }^{1}$ (D) . Ana Isabel Otero Sánchez ${ }^{2}$
}

Received: 15 July 2020 / Accepted: 25 June 2021 / Published online: 30 July 2021

(C) The Author(s) 2021

\begin{abstract}
In this article we will analyze the results, in terms of population, of the Common Agricultural Policy of the European Union, in a small European region, of one million inhabitants, with geographical characteristics typical of mountain agriculture. We will use spatial econometric techniques to verify whether the hypothesis that public spending destined for direct subsidization contributes positively to the territorial dynamics of certain relevant economic variables is fulfilled, specifically we will study in our case the population variable. From a methodological point of view, we will use several complementary approaches that give solidity to the results, always from the focus of spatial econometrics, essential when working with territorial data at a low level of disaggregation. On the one hand, we will carry out an exploratory spatial data analysis, which will allow us to detect possible patterns of spatial dependence, and then move on to a confirmatory analysis that will consider both, autocorrelation (models of lag and spatial error) and spatial heterogeneity (switching regressions). In addition to this cross-sectional data approach, which is based on a method of estimating the particular to the general, we will also use the estimation of spatial models of panel data, to include a temporal approach, with a method of estimating the general to the particular. The best results are obtained with a Spatial Durbin Model.
\end{abstract}

Keywords Spatial econometrics - Spatial Durbin model - Spatial panel data Switching regressions $\cdot$ Common agricultural policy

Oscar Luis Alonso Cienfuegos

oscarluis.alonso@unican.es

Ana Isabel Otero Sánchez

oteroana@uniovi.es

1 Department of Economy, Area of Quantitative Methods for Economy and Business,

University of Cantabria, Avenida de los Castros, s/n. 39005, Santander, Spain

2 Department of Quantitative Economics, Area of Financial Economics and Accounting, University of Oviedo, Avenida del Cristo, s/n. 33006, Oviedo, Spain 


\section{Introduction}

Depopulation is one of the fundamental problems that affect rural territories and that most worries policy makers responsible for designing cohesion policies, especially when they try to help stop the abandonment of these areas, especially linked to the primary sector, at least in relation to its history, culture and traditions. The Common Agricultural Policy (CAP) is and has been the set of economic policy measures of the European Union (EU) that has had more importance and weight within it, both from the financial point of view and from the point of view strategic. Most of the EU economic policy measures aimed at boosting activities and territories seek to contribute to job creation and population fixing, two of the key variables on which to obtain positive and broadly related results.

With this work we will try to contrast the possible contribution of the CAP to the population dynamics, in the case of the autonomous community of the Principality of Asturias, in the last programming period executed and completed (2007-2013). Based on the approach and methodology of spatial econometrics, we will try to verify whether public funds destined for the Asturian rural environment and co-financed by the European funds of both the first and second pillars of the CAP (EAGF and EAFRD respectively) have been relevant and have led to positive influence on the population dynamics of the territories that have benefited from such aid.We will divide our research into two parts. In the first we will use cross-sectional spatial models in a process of estimating the particular to the general. In the second part, we will estimate spatial models of panel data incorporating a temporal dynamic in a process of estimation from the general to the particular, which will allow us to contrast the results with both approaches, which we consider complementary.

The objectives, therefore, are to verify whether the hypothesis that CAP funds contribute as a whole to establishing population in rural areas is true or not, focusing on the case study of the Autonomous Community of the Principality of Asturias, and to verify, likewise, the need to use spatial econometric techniques that avoid statistical problems that could occur if they are ignored when we work with micro-territorial data.

We will begin with a brief review of the CAP in Asturias in the reference period, and then continue with a brief review of the literature regarding studies of the impacts of economic policy measures that involve associated investment or public expenditure for its execution. In the next section we will develop the methodology used, its adaptation to the project at hand and the rationale for the approach. Next, both the models and the results of the estimates obtained in our case are presented and described, to conclude with the conclusions, trying to help us to continue discussing the complex phenomenon of rural depopulation.

\section{The CAP in Asturias for 2007-2013}

The Principality of Asturias is located on the northern coast of Spain. Its territory occupies $10604 \mathrm{~km}^{2}$. The population is 1100000 . The most urban municipalities are concentrated in the center of the region, the four main ones being Oviedo, Gijón, 
Avilés and Siero. There are also urban and industrial structures in the regions of the Caudal and Nalón mining areas, with Mieres and Langreo as the most inhabited populations, but which are currently in a process of conversion and abandonment of coal mining. It is divided into 78 councils or municipalities, each of which has a capital or head town in which the town hall is located and which provides services to the rest of the surrounding villages and population centers. In total, the population units of Asturias are 6942. The orography is steep and mountainous and except for the nuclei previously described, the rest are rural. Competences in rural and agricultural matters are transferred from the Government of Spain to the Government of the Principality of Asturias, which is the one who implements and executes the CAP funds in its territory of action. The socio-economic context of the region is described in the PDR itself (Rural Development Program of the Principality of Asturias 2007-2013, 2013), which uses it as a starting point to justify the proposed policy regarding the second pillar. Among these socioeconomic characteristics we will highlight as a summary, how most relevant, the following:

1. Population in decline, aged, concentrated in the central area and with a tendency to increase in the urban area to the detriment of the rural population.

2. Gross domestic product (GDP) growth slower than in the whole of Spain.

3. In terms of convergence with the EU 25, measured in Purchasing Power Parity, Asturias is placed in the special group (phasing out) within the Convergence Objective.

4. Unemployment rate above the national average.

5. Population employed mainly in the service sector, followed by industry, construction and agriculture.

6. Business fabric composed mainly of small and medium enterprises (SMEs).

7. Small family farms and livestock farms.

8. High natural resources and an important network of protected areas.

Since the creation of the CAP, important reforms have taken place to adapt the initial objective of food supply in postwar Europe. In Spain, political competences, in relation to the primary sector, are transferred to the Autonomous Communities and Asturias sets its agricultural policy within the framework of the CAP, so that in recent years this determines the action and measures of the Principality of Asturias in agrolivestock and rural development matters, therefore, these reforms are not alien to the agricultural policy measures that affect its territory.

In the case of Asturias, as in the rest of Spain, the direct subsidy method is predominant in the execution of the CAP (Álvarez Ramos, 2008b), implicitly assuming that the transfer of public funds to the beneficiaries of aid has a positive effect on the economic variables affected, among which employment and income stand out, which should also contribute to energizing the population, object of this research (Rural Development Program of Principality of Asturias, 2013). The two Pillars of the CAP are those that support the policy of the Principality of Asturias, as in the rest of the autonomous communities, in what we can synthesize as direct aid to the sector, financed by EAGF, for the First Pillar, and Rural Development aid financed by the EAFRD, for the Second Pillar, that is, the PAC's own mechanism (Álvarez Ramos, 2008a). 
For the programming period considered, the pillars of the CAP are structured as follows:

1. The first pillar is that of market policies and includes direct aid, market regulation, and product information and promotion.

2. The second pillar is rural development.

We must bear in mind that the approach of the research presented will verify the possible impact of the CAP on a relevant variable, such as population, but that the objectives of the CAP are broader and that the funds allocated can be analyzed based on to other variables and performance. The nature of the funds and the design of the policy under study, of a non-specific nature and which is also proposed with a territorial approach, and even multisectoral in certain items, requires that the total funds be used, since there are no partial items specifically aimed exclusively at the variable under study. In addition, direct aid to the activity is supposed to have a clear component of contribution to the establishment of the population in the rural environment through the creation of employment and the need for management of the territory required by the activities of the primary sector. Some authors have determined that the CAP can have an impact even on employment in non-agricultural sectors, recording its impact beyond agriculture Rizov et al. (2018).

\section{Brief Literature Review}

The spatial econometrics approach is the methodological line that we will use to address this study theme. We will therefore cite some of the most relevant contributions in this more generic field, to later also analyze the different lines of research that have dealt with the study of the returns on public funds for territorial economic development. We will also consider this a generic field. And from the previous two we will specify the previous studies that are part of both, that is, the studies of the impacts of public policies on territorial development approached from the perspective of spatial econometrics, as is our case.

When working with data of a territorial nature, it is necessary to consider phenomena of spatial dependence between the observations, which could distort and invalidate the results by not complying with the required statistical properties. The set of estimation econometric techniques that consider these phenomena has been widely developed by different authors, especially from the 90 s of the 20th century. From that time we could cite as some of the most relevant works those of Rephann and Isserman (1994); Kopp (1995); Moreno et al. (1997); Kelejian and Robinson (1997); Boarnet (1998) and Gómez de Antonio (2001) among others.

We have considered the scientific contributions that, focusing on our own field of study, that is, the analysis of the impact or performance of public funds destined for economic development from a territorial perspective, have used econometrics with or without a spatial focus, finding the work by Pieokowski and Berkowitz (2015) relevant. These make a review of the most interesting (spatial and non-spatial), which fundamentally study the evolution of magnitudes such as Gross Domestic Product 
for all European regions, trying to determine the contribution of public capital to economic growth.

Fundamentally, either extensions to the spatial scope of neoclassical growth models have been used, such as Mohl and Hagen (2010), Lesage and Fisher (2008), Dall'Erba and Le Gallo (2008), Le Gallo et al. (2011), De Dominicis (2014) or also discontinuous spatial regression models such as Pellegrini et al. (2013) or Becker et al. (2010).

The specific impact on employment has also been studied with spatial econometric techniques, such as Mohl and Hagen (2011) or Vega and Elhorst (2017).

The results are not homogeneous and change depending on the different studies considered. Pieokowski and Berkowitz (2015) observe that positive results are generally obtained, but with little impact, especially in less developed regions. They also observe important differences between different territories. And finally they verify some results of no significant or even negative impact.

Mohl and Hagen (2011) only obtain statistically significant results when the funds are used as capital grants in areas where there is a low percentage of low-skilled population and have a negative impact in territories where the ratio of low-skilled population is very high, for So much so that no results are obtained to establish that EU funds promote employment.

For the specific case of spatial econometrics and demography Chi and Zhu (2008) review the link between the two, which includes the different demographic trends and theories as well as the different spatial econometric techniques and their convenience in these case studies, where the territorial distribution is relevant. Costa da Silva et al. (2016) use a dynamic spatial panel model to characterize the population dynamics in Brazil. Álvarez-Díaz et al. (2018) study the possible relationship between economic development and population growth using spatial models, concluding, in their case study, carried out for 28 European countries between 1960 and 2010, that there is a relationship bidirectional and positive between the two.

Regarding the specific studies of the impact of CAP funds with a spatial or territorial focus, in the spanish regions, as in our case, we will highlight the contributions of the following authors.

Nieto Masot and Gurría Gascon (2008) determine the unequal incidence in the Spanish region of Extremadura of the Leader funds, which are part of the second pillar, based on the socioeconomic characteristics of the application territories, which determines disparate results. Nieto Masot and Cárdenas Alonso (2017) also verify the unequal concentration of investments financed with Leader funds, which are higher in the more developed areas, also in the case of Extremadura. In Nieto Masot and Cárdenas Alonso (2018) it is concluded, using spatial analysis techniques, that the returns obtained in poorly developed rural areas in socio-economic terms by the Leader funds in Extremadura have been very low.

Sánchez Reyes (2011) is based on a population growth model, applied to the case of Extremadura, to study the phenomenon of rural depopulation and its relationship with welfare and agricultural subsidies. He determines the seriousness of the problem, attributable to multiple causes, and to the dependency relationship of several variables involved, determining the importance of territorial policies with specific actions according to the characteristics of each area. 
Nieto Masot et al. (2017) raise the need for a new regional distribution that they propose, for a better distribution of the territory, given the shortcomings and deficiencies of the current district.

Romero and Fernández-Serrano (2007) conclude that it is necessary, for greater efficiency and better results in the application of EU cohesion policy, among other things, to abandon the culture of "subsidy". Cejudo García and Navarro Valverde (2009), based on a case study from the province of Granada (Andalusia), determine that rural development policies have had an unequal effect on the territories, accentuating the center-periphery differences and contributing to rural depopulation in more isolated areas, due to the favorable effect on dynamic territories, to the detriment of the most depressed and those that lack centrality, thus aggravating their differences.

\section{Methodology}

We believe it is convenient to propose, given the nature of our study, and the peculiar socio-economic and geographical characteristics of Asturias a spatial econometrics approach. We will consider the phenomena of spatial autocorrelation and spatial heterogeneity for the specification of our models.

The methodological approach for the Exploratory Spatial Data Analysis (ESDA) and cross-section models is the one followed in Alonso Cienfuegos (2019). For the temporal analysis we will use the approach of Alonso Cienfuegos and Otero Sánchez (2019). We have considered it convenient to start initially with a series of variables with a previous theoretical relationship to analyze their behavior and functioning in different possible models and with different techniques to contrast the results in all cases and to reinforce them in the case at hand.

The approaches used can be divided into two main ones, one would be the one that considers cross-sectional data and a technique of selecting models from the particular to the general and another approach would be the one that considers temporal space data with a process from the general to the particular .

Both are complementary, since the transversal approach may be sufficient and provide relevant results, taking into account the variables of the entire programming period considered, and the temporal space approach can further detail the multiannual nature in the execution of the funds and programs object of study. We understand that if the results are coincident and follow the same line in both approaches we can obtain more solidity in the conclusions of our study.

We will propose several approaches, from the quantitative point of view, that allow us to contrast the results in order to improve or refute their robustness based on their coherence, so we will start with a ESDA, which can you give us clues about the spatial patterns in their distribution. We will also study the results of a cross-sectional analysis that includes spatial autocorrelation and heterogeneity, with a focus from the particular to the general, that includes spatial effects in the models if they exist, after the corresponding statistical verification as a result of the contrasts to the models that do not consider it in an initial phase. And in addition, given the possible limitations that we may encounter by not taking into account the time variable, we will propose a panel data model that does consider both dimensions, spatial and 
temporal, and with a focus, in this case from general to in particular, making contrasts to the models that include all spatial effects, to reach the most efficient after the corresponding statistical verification that discards the non-significant ones and validates those that are.

In our case we will base the ESDA on the statistical contrasts, without prejudice to the graphic methods, which in our case go in the same line of results, so we do not consider it necessary to abound in them, since they are clearly summarized both in the contrast of Moran's I, as in the LISA tests by zones, which allow us to sufficiently assess the spatial behavior of the variables initially considered.

For cross-section models we will carry out the so-called confirmatory analysis, where we will study, on the one hand, the possible existence of spatial autocorrelation, and on the other hand, the possible existence of spatial heterogeneity. The estimation method will be from specific to general.

For the spatial autocorrelation we will estimate the models by ordinary least squares, and in addition to the usual tests we will apply to the residuals the corresponding statistical tests to verify the existence or not of spatial dependence. These are the Moran I, and those based on the Lagrange multipliers, specifically the LMLAG, the LM-ERR, the robust LM-LAG, the robust LM-ERR and the LM-SARMA. They are going to give us information about the existence or not of spatial autocorrelation in the model and about the form of its incorporation, if it is present, depending on whether it is a substantive, residual spatial autocorrelation or both.

Its functional form follows the following general structure:

$$
\begin{gathered}
y=\rho W y+X \beta_{1}+W X \beta_{2}+u \\
u=\lambda W u+\varepsilon
\end{gathered}
$$

For spatial heterogeneity we will use spatial regimes to apply switching regressions. Structural instability is considered to be discrete and estimates as many values for the coefficients of a regression as structures or spatial regimes are established in the total sample of observations. The functional form is the same as in (1) and (2), but with as many "models" as we have considered.

For the spatial panel data model, the time variable is introduced, giving rise to the following specification:

$$
\begin{gathered}
y_{t}=\rho W y_{t}+x_{t} \beta+W x_{t} \gamma+\eta+\xi_{t} \tau+\varepsilon_{t} \\
\varepsilon_{t}=\lambda W \varepsilon_{t}+u_{t}
\end{gathered}
$$

Where:

$y_{t}$ is the vector corresponding to the endogenous variable.

$x_{t}$ is the matrix corresponding to the k exogenous variables.

$W$ is the spatial weigths matrix.

$\rho$ is the spatial lag vector of the endogenous variable.

$\beta$ is the parameter vector of explanatory variables.

$\gamma$ is the spatial lag parameter vector of explanatory variables.

$\varepsilon_{t}$ is the errors vector that follow a spatial autoregressive process.

$\lambda$ is the spatial lag vector of the autocorrelated error.

$u_{t}$ is the random error vector without spatial disturbances. 
$\eta \quad$ is the individual unobservable effects vector.

$\xi_{t} \quad$ is the temporary non-observable effect corresponding to time period t.

$\tau \quad$ is an vector of ones of dimension $(n \times 1)$.

The succession of proven methodologies and models will allow us to verify and compare the results obtained, to give them more solidity, in a process that integrates several approaches, which have in common the consideration of possible spatial phenomena, essential from the point statistically, given the nature of the data and the territory considered.

\section{Estimates and Results}

Table 1 shows the initial variables under analysis, on which we will perform the initial spatial exploratory analysis and which we will also consider for a first estimate of the models. The selection includes variables that are relevant from two points of view. On the one hand, the theoretical basis that justifies its possible causality, based mainly on the premises postulated by the economic policy measures under study, as they are variables that quantify aspects or magnitudes subject to investment by the funds that sustain these measures. On the other hand, we will also rely on the statistical significance required for inclusion. We will discard those that do not meet both criteria.

\section{ESDA}

In our case we will consider a univariate analysis focused on statistical contrasts, specifically those of Moran's I and the LISA tests by zones, which allow us to previously assess the possible existence of autocorrelation and/or spatial heterogeneity in the variables considered. Their results (Table 2) will be useful to propose the most convenient confirmatory analysis models.

For the public investment variable financed by EAFRD and EAGF (IPAC), the existence of spatial autocorrelation is detected. Both the contrasts based on the Moran Index (Moran, 1948), and the LISA tests (those based on the Moran I and also those based on the G of Getis and Ord (1992)), indicate the existence of clusters in councils from the west, as well as in others with a high weight in the primary sector.

For the variable dependent on our models, that is, the population (VPOBPAD), the Moran I test is not significant, which does not show spatial autocorrelation, but the LISA tests are, resulting in a clear concentration of clusters in the center and center-interior zone, suggesting patterns of dependence.

For the rest of the variables, we can consider two different groups in terms of the results for the spatial dependence analysis. It is not significant for non-agricultural variables, except for net family income, and it would be for the variables of the primary sector. A significant presence of clusters with local spatial autocorrelation is detected. These areas occupy the center of the region, except in the case of some agricultural variable (agricultural employment, agricultural production and number of head of cattle). 


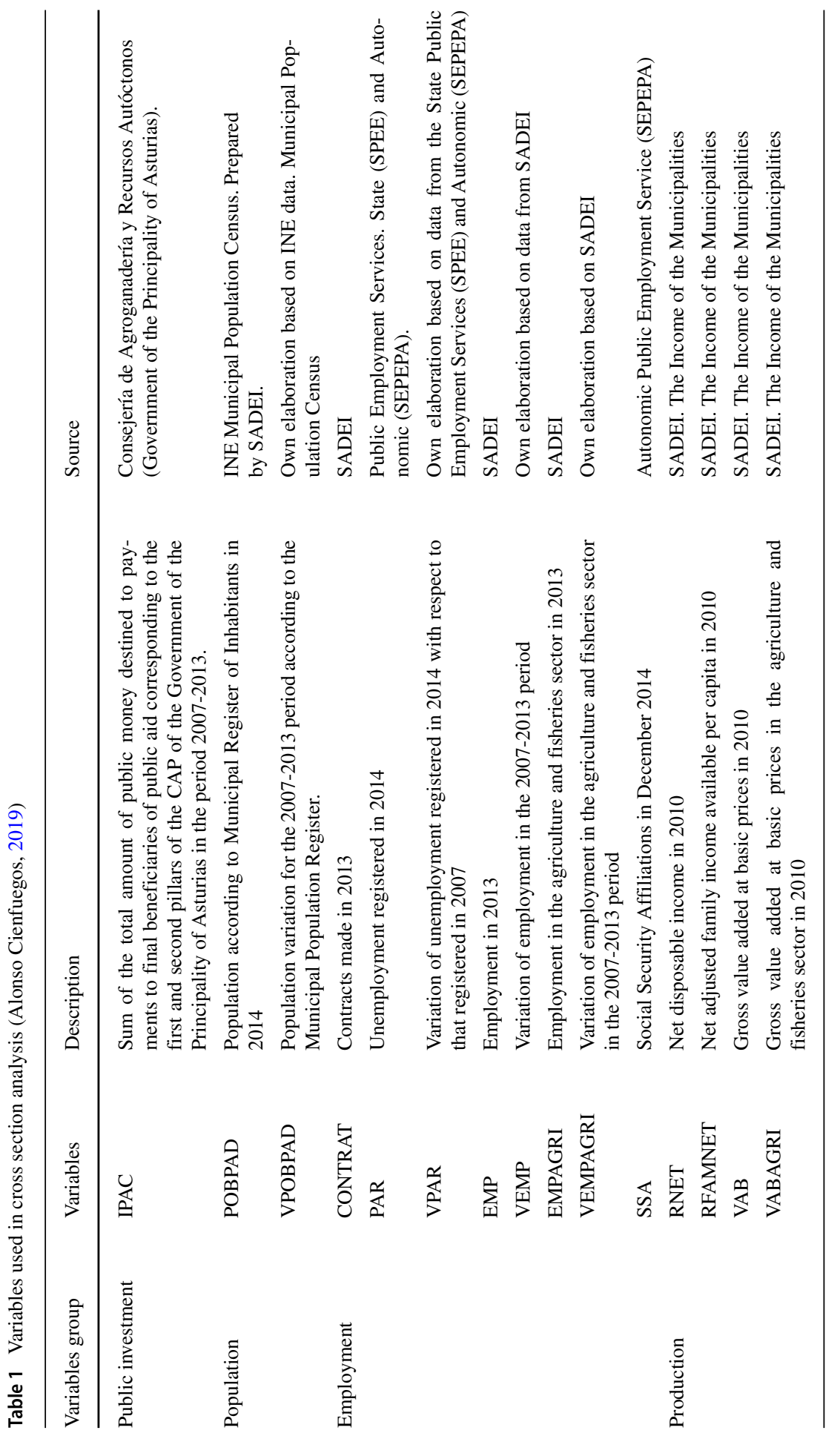




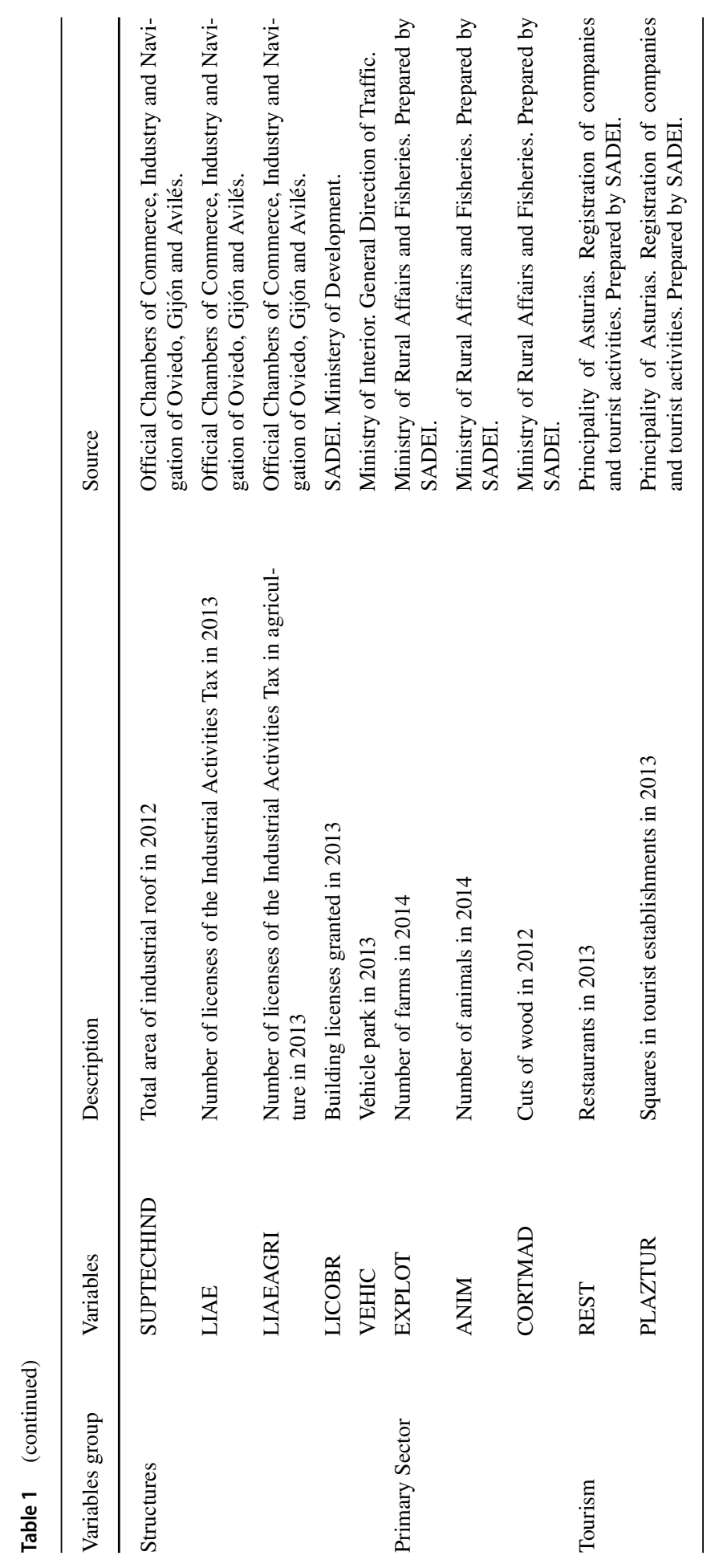




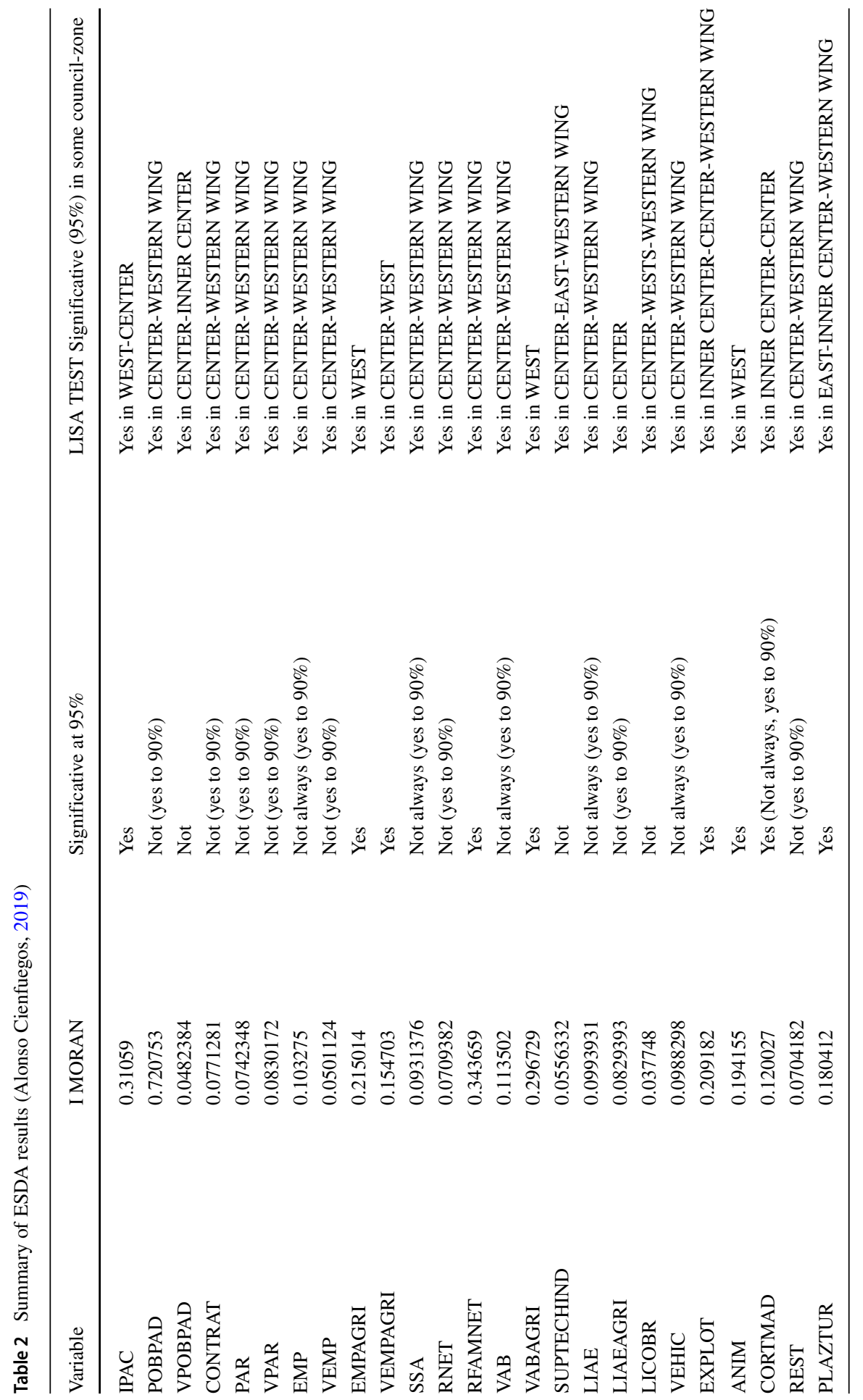


All this suggests the possibility of the existence of spatial heterogeneity, together with the autocorrelation described, so we will propose appropriate models for these cases. We have also detected the existence of extreme values that can affect the results, since in several variables the non-significant spatial autocorrelation becomes so when we eliminate the extreme values, so it seems appropriate, in the analysis of cross-sectional data, estimate on the one hand the models without outliers and on the other including them, to be able to compare the results.

For the estimation of models that consider the possible existence of spatial heterogeneity, we will use the Spatial Regimes approach, which divides the territory into non-homogeneous zones from one another from the economic point of view and in which the functional form of the models is changing. Based on the results of the ESDA and on territoriality criteria previously set by the administration as a management tool of the public funds under study, specifically in Local Action Groups that manage and execute the LEADER methodology, we have raised five zones or regimes on which we will later study its significance in terms of spatial heterogeneity that confirm, or not, the origin of its approach and consideration in those terms. The resulting areas are those that are collected on Fig. 1.

\section{Estimate Cross Section Models}

The estimated models that best explain are what we will call model 1 and model 2 , for the sample with outliers and without outliers respectively.

Model 1 (Table 3) is estimated by SWLS (Anselin \& Rey, 2014) by the robust method of heteroskedasticity (KP-HET), since in the previous step of estimation by $\mathrm{MCO}$, although the $\mathrm{KB}$ and $\mathrm{BP}$ tests were not significant, if it was the robust of White. By also rejecting the null hypothesis of normality of errors, this method is chosen to estimate the spatial error model, as suggested by the significance of the LM-ERR test, together with the non-significance of the LM-LAG. All coefficients are significant, including spatial lag. The matrix of spatial weights is contiguous queen type.

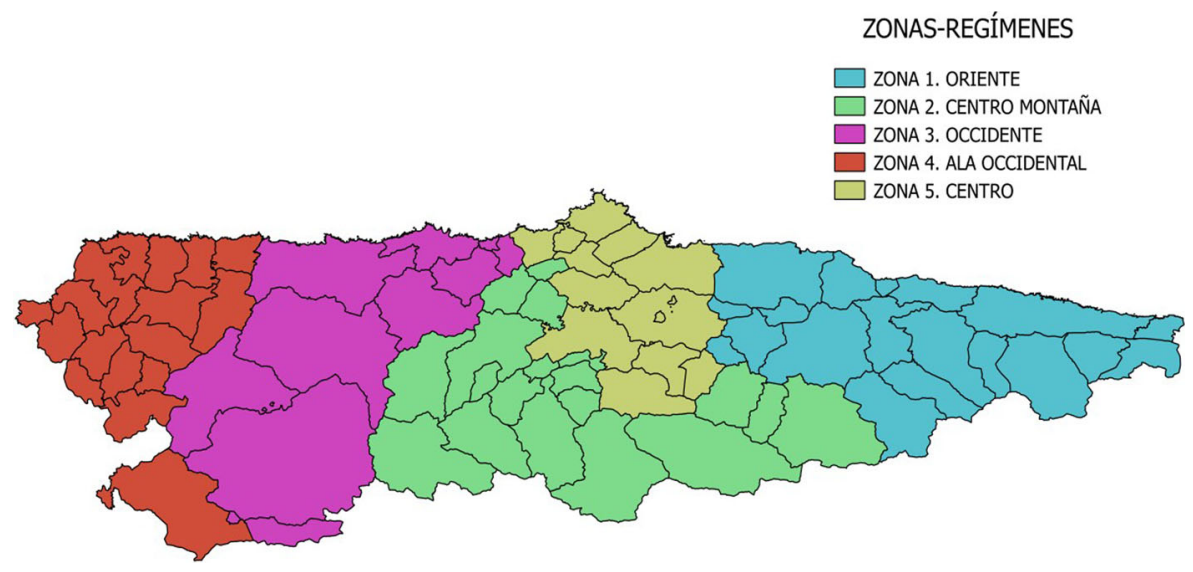

Fig. 1 Spatial regimes zones (Alonso Cienfuegos, 2019) 
Table 3 Model 1

\begin{tabular}{|c|c|c|c|c|}
\hline \multicolumn{5}{|c|}{ Dependent variable: VPOBPAD } \\
\hline Variable & Coefficient & Standar Error & Z-Statistic & Probability \\
\hline Constant & -44.1628291 & 113.0763140 & -0.3905577 & 0.6961242 \\
\hline$\beta_{1}$ IPAC & -0.0000124 & 0.0000049 & -2.5343588 & 0.0112653 \\
\hline$\beta_{2} \mathrm{RNET}$ & 0.0063300 & 0.0008996 & 7.0361389 & 0.0000000 \\
\hline$\beta_{3}$ VEMP & -1.4728552 & 0.1755891 & -8.3880778 & 0.0000000 \\
\hline$\lambda$ & 0.5059038 & 0.1454666 & 3.4778005 & 0.0005055 \\
\hline
\end{tabular}

Pseudo R-squared: 0.7068

Estimation metod: Spatially Weighted Least SquareS (HET)

Spatial matrix weights:contiguity queen type standardized by rows

We are going to estimate this model for the sample without outliers, trying to eliminate its possible effect on the total of the sample, since they can condition the previous results and distort the conclusions obtained, especially since the six councils eliminated are those that have the urban structure most important in the entire region and these urban areas are not in principle beneficiaries of aid to rural areas. Oviedo, Gijón, Avilés, Mieres, Langreo and Siero (all with a population greater than 40000 inhabitants) are eliminated from the sample.

Coefficients are obtained with values in highly significant individual significance tests. The three coefficients of the explanatory variables have a negative sign. In the case of RNET it is justified by the greater loss of population in the councils with the highest level of income, since these councils coincide with the largest, in a general context of population and economic decline.

The model estimated by two stage least squares, using a rook type contiguity matrix for the analysis of spatial dependence, does not require the use of a spatial lag model, spatial error or combination of both, since the spatial dependence tests are not significant, both in the initial estimate by minimum least squares, as in the second by two stage least squares method. By not obtaining normal errors this method is used, obtaining the model 2 as the best considered (Table 4).

The variables CONTRAT and VEMP have significant coefficients individually and with a positive sign, which means that high and positive values contribute to obtain values of population variation in the period that are also high and positive. The opposite occurs with IPAC, which has a negative and very small value, which indicates a negative contribution where the greater the investment the worse the variation, so it does not seem, based on these data, that the objectives pursued by these policies have been achieved in terms of population.

\section{Estimate cross section models considering spatial regimes}

After a process in which after the first estimate by ordinary least squares, the heterocedasticity improves, also the normality of the errors, the multicollinearity is low, the joint and individual significance of the variables is positive and the spatial 
Table 4 Model 2

\begin{tabular}{|c|c|c|c|c|}
\hline Variable & Coefficient & Standar Error & Z-Statistic & Probability \\
\hline Constant & -46.7288451 & 39.1309776 & -1.1941650 & 0.2324134 \\
\hline$\beta_{1}$ CONTRAT & 0.1856740 & 0.0240166 & 7.7310805 & 0.0000000 \\
\hline$\beta_{2}$ IPAC & -0.0000130 & 0.0000027 & -4.9036147 & 0.0000009 \\
\hline$\beta_{3}$ VEMP & 1.0601361 & 0.1309312 & 8.0968967 & 0.0000000 \\
\hline
\end{tabular}

Pseudo R-squared: 0.6369

Estimation metod: Two stage least squares

Instrumented: CONTRAT

Instruments: LIAE, RNET

Spatial matrix weights: contiguity rook type standardized by rows

Anselin-Kelejian Test: valor $=0.721$ p-valor $=0.3957$

dependence tests point to an error model or mixed, mixed model of lag and spatial error (combo) estimated by spatially weighted two-squared least squares (GSW2SLS) is selected as more appropriate by the method of Kelijian and Prucha (2010) robust to heteroskedasticity, with a matrix of spatial weights rook type (see Table 5).

Chow test is significative for all variables individually and also globally (see Table 6). The sign of the variables is negative in the case of IPAC, for the second and fourth regimes, in which they are significant, since in the rest they are not, and positive for RNET and VEMP in all areas except in zone five, Central area more "urban."

As we did before, in the models that did not consider parametric instability, we are going to estimate again the models with the sample that eliminates those councils with higher values in the majority of variables considered, which coincide with the councils with more urban nuclei.

In this case it is convenient to use spatial models. The model that best explains is a mixed lag and error model estimated by spatially weighted two-stage least squares, using the proposal of Kelijian and Prucha (2010), GSW2SLS (HET). The results are shown in Table 7.

Again, IPAC has a negative sign in the areas where it is significant. The model shows the parametric instability between the different study areas, although the Chow test is not significant for VEMP, nor for the spatial lag of the endogenous, nor for the error lag, if it is for the rest of the variables as well as globally (see Table 8). Heteroskedasticity has improved the normality of errors and the heterogeneity and spatial dependence have been corrected with respect to the model without spatial regimes.

\section{Estimate Spatial Panel Data}

Table 9 shows the descriptive analysis of the variables used to estimate the models based on spatial panel data. We can admit a positive relationship between unemployment 
Table 5 Model 3

\begin{tabular}{lllll}
\hline Variable & Coefficient & Standar Error & Z-Statistic & ProbabiliTY \\
\hline ZONE 1 : EAST & & & & \\
Constant & -59.3050663 & 75.2208773 & -0.7884123 & 0.4304556 \\
$\beta_{1}$ IPAC & 0.0000009 & 0.0000076 & 0.1175516 & 0.9064230 \\
$\beta_{2}$ RNET & 0.0026040 & 0.0007878 & 3.3054513 & 0.0009482 \\
$\beta_{3}$ VEMP & 0.7325867 & 0.3074283 & 2.3829511 & 0.0171745 \\
$\rho$ W VP PBPAD & 0.4111255 & 0.2317320 & 1.7741425 & 0.0760396 \\
$\lambda$ & -0.7931191 & 0.3576608 & -2.2175177 & 0.0265877
\end{tabular}

Pseudo R-squared: 0.3735

ZONE 2 : MOUNTAIN CENTER

$\begin{array}{lllll}\text { Constant } & 79.6585366 & 28.2952951 & 2.8152573 & 0.0048738 \\ \beta_{1} \text { IPAC } & -0.0000196 & 0.0000031 & -6.2316525 & 0.0000000 \\ \beta_{2} \text { RNET } & -0.0003353 & 0.0009389 & -0.3570793 & 0.7210324 \\ \beta_{3} \text { VEMP } & 0.7325867 & 0.3074283 & 2.3829511 & 0.0171745 \\ \rho W \cdot V P O B P A D & 0.2051332 & 0.0976925 & 2.0997854 & 0.0357477 \\ \lambda & -0.9999999 & 0.2674744 & -3.7386758 & 0.0001850\end{array}$

Pseudo R-squared:0.7965

ZONE 3 : WEST

Constant
$\beta_{1}$ IPAC
$\beta_{2}$ RNET
$\beta_{3}$ VEMP
$\rho W \cdot V P O B P A D$
$\lambda$

273.1372289

95.4451909

2.8617181

0.0042135

$-0.0000045$

0.0000024

$-1.8883206$

0.0589829

$-0.0054954$

0.0012550

$-4.3787857$

0.0000119

0.1614087

0.0903555

1.7863738

0.0740388

0.2659463

0.0682282

3.8978933

0.0000970

$-0.9999999$

1.8216493

$-0.5489531$

0.5830377

Pseudo R-squared:0.9494

ZONE 4 : WESTERN WING

Constant
$\beta_{1}$ IPAC
$\beta_{2}$ RNET
$\beta_{3}$ VEMP
$\rho W \cdot V P O B P A D$
$\lambda$

$-18.0745008$

33.6806802

$-0.5366430$

0.5915142

$-0.0000167$

0.0000020

$-8.2755364$

0.0000000

0.0027978

0.0007126

3.9263601

0.0000862

0.9615930

0.2296168

4.1878170

0.0000282

$-0.0313375$

0.1863676

$-0.1681486$

0.8664664

0.0929086

0.3773789

0.2461944

0.8055317

Pseudo R-squared:0.6940

ZONE 5 : CENTER

$\begin{array}{lllll}\text { Constant } & 255.1099601 & 952.8321527 & 0.2677386 & 0.7889005 \\ \beta_{1} \text { IPAC } & 0.0000072 & 0.0000408 & 0.1767860 & 0.8596765 \\ \beta_{2} \text { RNET } & -0.0074060 & 0.0006306 & -11.7445258 & 0.0000000 \\ \beta_{3} \text { VEMP } & -1.6795816 & 0.1251074 & -13.4251205 & 0.0000000\end{array}$


Table 5 (continued)

\begin{tabular}{lllll}
\hline Variable & Coefficient & Standar Error & Z-Statistic & Probability \\
\hline$\rho W \cdot$ V POBPAD & -0.2505184 & 0.1525016 & -1.6427261 & 0.1004396 \\
$\lambda$ & 0.7511778 & 0.1675096 & 4.4843861 & 0.0000073 \\
Pseudo R-squared:0.8060 & & & \\
\hline
\end{tabular}

Dependent variable: VPOBPAD

Estimation metod:Generalized Spatially Weighted Two Stage Least Squares model (HET)

Instrumented: $W \cdot V P O B P A D$

Instruments: $W \cdot I P A C, W \cdot R N E T, W \cdot V E M P$

Spatial matrix weights: contiguity rook type standardized by rows

and the population (without prejudice to possible variations in this regard). The highest number of unemployed in search of employment is expected to occur in the most populated and urbanized councils, as there is also a context of generalized economic crisis for the reference period, but without forgetting that there could also be a contrary relationship, because it has these councils effect expulsion towards councils with more levels and employment opportunities that attract population.

Alonso-Villar et al. (2009) analyze the structure of unemployment by municipalities in Spain and consider that the population size of these favors the search and attainment of employment, giving the lowest levels of unemployment rates in large cities, but from a level minimum, which are mainly found in the large cities of other autonomous communities other than the Asturian. On the contrary, there are the highest levels of unemployment in medium-sized cities, and significant dispersion in smaller municipalities (compared to the lower levels of large cities).

In any case, we consider that the sign of this relationship can always be distorted by the connections between rural and urban areas, as well as by the strong supramunicipal links existing in the Asturian socio-economic reality. There are different regional realities, as well as a strong polarization around the center of the region, to the detriment of the eastern and western wings (Rural Development Program of Principality of Asturias, 2013). We therefore expect a positive relationship between these

Table 6 Chow test of Model 3

\begin{tabular}{lll}
\hline Chow Test & & \\
\hline Variable & Value & P-Value \\
\hline Constant & 12.680 & 0.0130 \\
$\beta_{1}$ IPAC & 949.437 & 0.0000 \\
$\beta_{2}$ RNET & 162.785 & 0.0000 \\
$\beta_{3}$ VEMP & 227.782 & 0.0000 \\
$\rho W \cdot V P O B P A D$ & 11.902 & 0.0181 \\
$\lambda$ & 38.622 & 0.0000 \\
GLOBAL TEST & 24.074 & 0.0001 \\
\hline
\end{tabular}


Table 7 Model 4

\begin{tabular}{lllll}
\hline Variable & Coefficient & Standar Error & Z-Statistic & Probability \\
\hline ZONE 1 : EAST & & & & \\
Constant & -25.7796029 & 66.2835118 & -0.3889293 & 0.6973284 \\
$\beta_{1}$ CONTRAT & 0.1270776 & 0.0470730 & 2.6995848 & 0.0069426 \\
$\beta_{2}$ IPAC & -0.0000005 & 0.0000075 & -0.0645728 & 0.9485142 \\
$\beta_{3}$ VEMP & 0.7745191 & 0.3041466 & 2.5465323 & 0.0108799 \\
$\rho W \cdot V P O B P A D$ & 0.2677326 & 0.1725262 & 1.5518370 & 0.1207012 \\
$\lambda$ & -0.8371299 & 0.3667534 & -2.2825415 & 0.0224574
\end{tabular}

Pseudo R-squared:0.4070

ZONE 2 : MOUNTAIN CENTER

$\begin{array}{lllll}\text { Constant } & 85.7884117 & 33.2959053 & 2.5765454 & 0.0099793 \\ \beta_{1} \text { CONTRAT } & -0.0202698 & 0.0828593 & -0.2446297 & 0.8067432 \\ \beta_{2} \text { IPAC } & -0.0000195 & 0.0000032 & -6.0045037 & 0.0000000 \\ \beta_{3} \text { VEMP } & 0.8103160 & 0.1611452 & 5.0284820 & 0.0000005 \\ \rho W \cdot V P O B P A D & 0.2581287 & 0.1217801 & 2.1196289 & 0.0340374 \\ \lambda & -0.9999999 & 0.2699593 & -3.7042624 & 0.0002120\end{array}$

Pseudo R-squared:0.7860

ZONE 3 : WEST

Constant
$\beta_{1}$ CONTRAT
$\beta_{2}$ IPAC
$\beta_{3}$ VEMP
$\rho W \cdot V P O B P A D$
$\lambda$

334.8529043

$-0.2873099$

$-0.0000060$

0.6484948

0.3039132

$-0.4359652$

Pseudo R-squared:0.9230

ZONE 4 : Western Wing

Constant
$\beta_{1}$ CONTRAT
$\beta_{2}$ IPAC
$\beta_{3}$ VEMP
$\rho W \cdot V P O B P A D$
$\lambda$

Pseudo R-squared:0.7130

ZONE 5 : CENTER

Constant
$\beta_{1}$ CONTRAT
$\beta_{2}$ IPAC
$\beta_{3}$ VEMP

-37.8740075
0.1523662
-0.0000115
0.9780488
-0.1256239
0.4521837

34.8555614
0.0326036
0.0000019
0.1677968
0.2292206
0.4216706

$-1.0865987$

4.6732937

$-6.1068007$

5.8287702

$-0.5480480$

1.0723626
0.1049787 0.0024353 0.0431665 0.0028038 0.0306145 0.6070699

0.2772142 0.0000030 0.0000000 0.0000000 0.5836590 0.2835572

$\begin{array}{llll}-398.0258814 & 245.7576387 & -1.6195870 & 0.1053210 \\ 0.3033120 & 0.0864340 & 3.5091759 & 0.0004495 \\ -0.0000600 & 0.0000320 & -1.8744797 & 0.0608643 \\ 1.8807645 & 0.6142308 & 3.0619833 & 0.0021988\end{array}$


Table 7 (continued)

\begin{tabular}{lllll}
\hline Variable & Coefficient & Standar Error & Z-Statistic & Probability \\
\hline$\rho W \cdot$ V POBPAD & 1.5081880 & 0.9399949 & 1.6044641 & 0.1086118 \\
$\lambda$ & -0.8208259 & 0.4989450 & -1.6451230 & 0.0999444 \\
Pseudo R-squared:0.6582 & & & & \\
\hline
\end{tabular}

Dependent variable: VPOBPAD

Estimation metod: Generalized Spatially Weighted Two Stage Least Squares model (HET)

Instrumented: $W \cdot V P O B P A D$

Instruments: $W \cdot C O N T R A T, W \cdot I P A C, W \cdot V E M P$

Spatial matrix weights: contiguity queen type standardized by rows

variables, given the distribution and characteristics of the population in Asturias, but being able to accept changes in this regard, given the situation and circumstances described.

The model to be estimated, in a process of estimating the general to the specific, has the following functional form:

$$
\begin{gathered}
\text { pob }_{t}=\rho \text { Wpob }_{t}+\text { ipac }_{t} \beta_{1}+\text { emp }_{t} \beta_{2}+\text { empagri }_{t} \beta_{3}+\text { paro }_{t} \beta 4+\text { Wipac }_{t} \gamma_{01}+ \\
+ \text { Wemp }_{t} \gamma_{02}+\text { Wempagri }_{t} \gamma_{03}+\text { Wparo }_{t} \gamma_{04}+\eta+\varepsilon_{t} \\
\varepsilon_{t}=\lambda W \varepsilon_{t}+u_{t}
\end{gathered}
$$

The joint control of the unobservable effects could cause us problems, therefore, we will only consider unobservable individual effects, not including temporary effects, to avoid a significant loss of degrees of freedom, as well as the possible existence of multicollinearity, which could distort the results of the estimates.

We use the Panel Data Toolbox v2.0 package developed by Álvarez et al. (2017) for Matlab. The estimation method is that of instrumental variables, if only the spatial lag of the endogenous is included, and that of generalized moments, if spatial lag is included in the structure of the error.

Table 8 Chow test of Model 4

\begin{tabular}{lll}
\hline $\begin{array}{l}\text { Chow Test } \\
\text { cmidrule1-3 Variable }\end{array}$ & Value & P-Value \\
\hline Constant & 12.353 & 0.0149 \\
$\beta_{1}$ CONTRAT & 26.807 & 0.0000 \\
$\beta_{2}$ IPAC & 14.034 & 0.0072 \\
$\beta_{3}$ VEMP & 4.379 & 0.3571 \\
$\rho W \cdot V P O B P A D$ & 4.619 & 0.3287 \\
$\lambda$ & 8.950 & 0.0624 \\
GLOBAL TEST & 206.722 & 0.0000 \\
\hline
\end{tabular}


Table 9 Descriptive analysis of spatial panel data estimation variables

\begin{tabular}{|c|c|c|c|c|}
\hline Variables & Mean & Standard deviation & Expected sign & Source \\
\hline POB & 0.0049441 & 0.0052848 & - & $\begin{array}{l}\text { INE Municipal Population } \\
\text { Census. Prepared by SADEI. }\end{array}$ \\
\hline IPAC & 0.0000013463 & 0.0000016352 & Positive & $\begin{array}{l}\text { Consejería de Agroganadería } \\
\text { y Recursos Autóctonos (Gov- } \\
\text { ernment of the Principality of } \\
\text { Asturias). }\end{array}$ \\
\hline EMP & 0.0016315 & 0.0023220 & Positive & SADEI \\
\hline EMPAGRI & 206.1468 & 235.0672 & Positive & SADEI \\
\hline PARO & 269.2898 & 353.3792 & $\begin{array}{l}\text { Negative or } \\
\text { Positive }\end{array}$ & $\begin{array}{l}\text { Public Employment Services. } \\
\text { State (SPEE) and Autonomous } \\
\text { (SEPEPA). }\end{array}$ \\
\hline
\end{tabular}

For the selection of the spatial weights matrices we will compare the results of the models with different types, specifically with contiguity relations matrices with 4, 5 or 6 neighbors based on inverse or binary distance, and standardized by rows or without standardization. We will use a spatial Durbin model with random effects. With these scenarios we will compare the results of the criteria proposed by Elhorst et al. (2013), which suggest considering the residual variance. We will choose the matrix that provides the best values for it by changing only the matrix in the model, keeping the rest of the structure, variables and parameters identical. The spatial matrix to be used, to obtain better results of the residual variance in the estimation, will be the one that considers four neighbors, binary and standardized by rows.

Tables 10 and 11 shows the results of the estimates when the variable "pob" is dependent. The different models are proposed, Durbin, Durbin error, lag and spatial error. Starting from the general nested model, we conclude that the most appropriate is the Spatial Durbin Model, with random individual effects, considering the spatial lag of the employment variable as significant. The results of other options are also presented, to compare them with each other, and also compare the possible behavior of the variable related to public investment in the Common Agricultural Policy in Asturias, under other possible specifications. There is a clear lack of significance of the "ipac" variable that does not allow its impact to be considered relevant, at least in terms favorable to population dynamics. The "ipac" coefficient is not significant in any of the models proposed, except in the lag and spatial error model, estimated by random effects, but it is the only case in which the Hausman test clearly indicates rejecting the null hypothesis and choosing the fixed effects model versus the random effects model.

When comparing the convenience between models with fixed or random effects, we have encountered the disadvantage that some of the Hausman test statistic values are negative. The cause may be that the sample is not large enough and calculation problems are generated in the program, since in theory this should not happen. It can be interpreted as a test that prevents us from rejecting the null hypothesis, at least as shown in the Stata (2005), but this cannot make us accept $H_{0}$, since it can also occur 
Table 10 Results of spatial panel data estimation with fixed effects

\begin{tabular}{|c|c|c|c|c|c|}
\hline Variable & SLM & SEM & SLEM & SDM & SDEM \\
\hline$\beta_{1}$ ipac & $\begin{array}{l}-0.000016 \\
(0.219)\end{array}$ & $\begin{array}{l}0.000 \\
(0.986)\end{array}$ & $\begin{array}{l}-0.000015 \\
(0.245)\end{array}$ & $\begin{array}{l}-0.000019 \\
(0.201)\end{array}$ & $\begin{array}{l}-0.000005 \\
(0.644)\end{array}$ \\
\hline$\beta_{2} \mathrm{emp}$ & $\begin{array}{l}0.153631 \\
(0.000)\end{array}$ & $\begin{array}{l}0.189015 \\
(0.000)\end{array}$ & $\begin{array}{l}0.155222 \\
(0.000)\end{array}$ & $\begin{array}{l}0.133586 \\
(0.004)\end{array}$ & $\begin{array}{l}0.253931 \\
(0.000)\end{array}$ \\
\hline$\beta_{3}$ empagri & $\begin{array}{l}0.659301 \\
(0.003)\end{array}$ & $\begin{array}{l}1.241577 \\
(0.000)\end{array}$ & $\begin{array}{l}0.762912 \\
(0.000)\end{array}$ & $\begin{array}{l}0.424022 \\
(0.116)\end{array}$ & $\begin{array}{l}1.102515 \\
(0.000)\end{array}$ \\
\hline$\beta_{3}$ paro & $\begin{array}{l}-0.047870 \\
(0.412)\end{array}$ & $\begin{array}{l}-0.161103 \\
(0.006)\end{array}$ & $\begin{array}{l}-0.015189 \\
(0.770)\end{array}$ & $\begin{array}{l}-0.097162 \\
(0.149)\end{array}$ & $\begin{array}{l}-0.097069 \\
(0.102)\end{array}$ \\
\hline$\rho$ & $\begin{array}{l}0.028263 \\
(0.000)\end{array}$ & - & $\begin{array}{l}0.024377 \\
(0.000)\end{array}$ & $\begin{array}{l}0.039484 \\
(0.000)\end{array}$ & - \\
\hline$\gamma_{01}$ & - & - & - & - & - \\
\hline$\gamma_{02}$ & - & $\begin{array}{l}- \\
-\end{array}$ & - & $\begin{array}{l}-0.004701 \\
(0.009)\end{array}$ & $\begin{array}{l}0.006995 \\
(0.000)\end{array}$ \\
\hline$\gamma_{03}$ & - & - & - & - & - \\
\hline$\gamma_{04}$ & - & - & - & - & $\begin{array}{l}0.002029 \\
(0.340)\end{array}$ \\
\hline$\lambda$ & - & $\begin{array}{l}0.007760 \\
(1.000)\end{array}$ & $\begin{array}{l}-0.005661 \\
(1.000)\end{array}$ & - & $\begin{array}{l}0.008251 \\
(1.000)\end{array}$ \\
\hline Constant & - & - & $\begin{array}{l}- \\
-\end{array}$ & - & - \\
\hline$R^{2}$ & 0.11004 & 0.53630 & 0.12070 & 0.09183 & 0.48110 \\
\hline WALD & $\begin{array}{l}247.638670 \\
(0.000)\end{array}$ & $\begin{array}{l}201.187167 \\
(0.000)\end{array}$ & $\begin{array}{l}290.079610 \\
(0.000)\end{array}$ & $\begin{array}{l}200.901980 \\
(0.000)\end{array}$ & $\begin{array}{l}236.113687 \\
(0.000)\end{array}$ \\
\hline HAUSSMAN & Negative & Negative & Negative & Negative & Negative \\
\hline Wooldridge & - & $\begin{array}{l}278177.8917 \\
(0.000)\end{array}$ & - & $\begin{array}{l}261861.5108 \\
(0.000)\end{array}$ & $\begin{array}{l}266435.6562 \\
(0.000)\end{array}$ \\
\hline BLSERIAL & - & - & - & - & - \\
\hline PESARAN & - & $\begin{array}{l}9.468976 \\
(0.000)\end{array}$ & - & - & $\begin{array}{l}4.236269 \\
(0.000)\end{array}$ \\
\hline BSJK & $\begin{array}{l}349.9513 \\
(0.000)\end{array}$ & $\begin{array}{l}349.9513 \\
(0.000)\end{array}$ & $\begin{array}{l}349.9513 \\
(0.000)\end{array}$ & $\begin{array}{l}349.9513 \\
(0.000)\end{array}$ & $\begin{array}{l}349.9513 \\
(0.000)\end{array}$ \\
\hline
\end{tabular}

asymptotically, in some types of models, when $H_{1}$ is true (Schreiber, 2008 ). In any case, the calculated statistics, as well as the rest of the indicators presented, advise us to opt for the random effects model. 
Table 11 Results of spatial panel data estimation with random effects

\begin{tabular}{|c|c|c|c|c|c|}
\hline \multicolumn{6}{|c|}{ Ramdom Effects Estimation (In brackets the p-value) } \\
\hline Variable & SLM & SEM & SLEM & SDM & SDEM \\
\hline \multirow[t]{2}{*}{$\beta_{1}$ ipac } & 0.000034 & -0.000108 & 0.000037 & 0.000020 & -0.000155 \\
\hline & $(0.219)$ & $(0.382)$ & $(0.002)$ & $(\mathbf{0 . 5 1 9 )}$ & $(0.103)$ \\
\hline \multirow[t]{2}{*}{$\beta_{2} \mathrm{emp}$} & 0.912608 & 0.537566 & 0.899267 & 1.042541 & 0.745340 \\
\hline & $(0.000)$ & $(0.000)$ & $(0.000)$ & $(\mathbf{0 . 0 0 0 )}$ & $(0.000)$ \\
\hline \multirow[t]{2}{*}{$\beta_{3}$ empagri } & 2.051698 & 6.900628 & 2.088952 & 2.117110 & 5.463896 \\
\hline & $(0.000)$ & $(0.000)$ & $(0.000)$ & $(\mathbf{0 . 0 0 0 )}$ & $(0.000)$ \\
\hline \multirow[t]{2}{*}{$\beta_{3}$ paro } & 0.923020 & 8.640076 & 0.906771 & 1.287084 & 8.247142 \\
\hline & $(0.000)$ & $(0.000)$ & $(0.000)$ & $(0.000)$ & $(0.000)$ \\
\hline \multirow[t]{2}{*}{$\rho$} & 0.003574 & - & 0.006378 & 0.008465 & - \\
\hline & $(0.000)$ & - & $(0.000)$ & $(\mathbf{0 . 0 0 0 )}$ & - \\
\hline \multirow[t]{2}{*}{$\gamma_{01}$} & - & - & - & - & - \\
\hline & - & - & - & - & - \\
\hline \multirow[t]{2}{*}{$\gamma_{02}$} & - & - & - & 0.015034 & 0.011074 \\
\hline & - & - & - & $(0.001)$ & $(0.000)$ \\
\hline \multirow[t]{2}{*}{$\gamma_{03}$} & - & - & - & - & - \\
\hline & - & - & - & - & - \\
\hline \multirow[t]{2}{*}{$\gamma_{04}$} & - & - & - & - & -0.078566 \\
\hline & - & - & - & - & $(0.000)$ \\
\hline \multirow[t]{2}{*}{$\lambda$} & - & 0.033915 & -0.005661 & - & 0.006601 \\
\hline & - & $(1.000)$ & $(1.000)$ & - & $(1.000)$ \\
\hline \multirow[t]{2}{*}{ Constant } & 2054.373046 & 551.642826 & 1456.685637 & 3046.541894 & 706.802537 \\
\hline & $(0.000)$ & $(0.036)$ & $(0.000)$ & $(0.000)$ & $(0.001)$ \\
\hline$R^{2}$ & 0.69023 & 0.90783 & 0.65186 & 0.69606 & 0.91027 \\
\hline \multirow[t]{2}{*}{ WALD } & 423.249913 & 1645.764827 & 3171.963268 & 443.374172 & 2142.314181 \\
\hline & $(0.000)$ & $(0.000)$ & $(0.000)$ & $(0.000)$ & $(0.000)$ \\
\hline \multirow[t]{2}{*}{ HAUSSMAN } & Negative & Negative & 2272.711915 & Negative & Negative \\
\hline & & & $(0.000)$ & & \\
\hline \multirow[t]{2}{*}{ Wooldridge } & - & - & - & - & - \\
\hline & - & - & - & - & - \\
\hline \multirow[t]{2}{*}{ BLSERIAL } & - & 385.815767 & - & - & 385.815767 \\
\hline & - & $(0.000)$ & - & - & $(0.000)$ \\
\hline \multirow[t]{2}{*}{ PESARAN } & - & 84.389879 & - & - & 4.461688 \\
\hline & - & $(0.000)$ & - & - & $(0.000)$ \\
\hline \multirow[t]{2}{*}{ BSJK } & 349.9513 & 349.9513 & 349.9513 & 349.9513 & 349.9513 \\
\hline & $(0.000)$ & $(0.000)$ & $(0.000)$ & $(0.000)$ & $(0.000)$ \\
\hline
\end{tabular}


In all cases the coefficient of the spatial lag error is not significant, so a spatial Durbin model is chosen, although with a single spatial lag in the exogenous ones, specifically in the variable related to the number of employment, "emp". The endogenous spatial lag model, with random effects, would also be acceptable.

The performance of the LM-lag, LM-error tests performed on the residuals of the estimate by MCO, using the routine for Matlab proposed by Elhorst (2014), which would be typical of a process from the specific to the general, also indicate the existence of substantive and non-residual spatial dependence, thus coinciding with this result.

The signs of the coefficients of the explanatory variables are the expected ones, of positive sign, as well as in the spatial lag of the explained one and of the explanatory one, showing signs of a positive relationship with respect to the behavior of the population before high values of the same variable in neighboring locations. The same applies to the employment variable, which shows a favorable impact on the population of neighboring councils.

\section{Discussion and Conclusions}

\section{Discussion}

On the results of the analysis, different scenarios and hypotheses that are presented for discussion can be raised, since they are affected by different factors, typical of a chain with multiple participating agents, both in the design and in the execution of rural development plans and of the community agrarian policy as a whole.

1. The lack of quantitative evidence that shows a positive association between public spending carried out within the framework of the CAP and the population for the reference period and territory perhaps raises the possibility that the objectives pursued in terms of population may be too ambitious for the scope of the investments proposed and are part of a set that can help to stop or alleviate adverse socio-economic effects, by way of subsidy, but not to contribute as an engine of socio-economic and population development. The problem of rural depopulation follows an upward trend, with a multifactorial explanation that probably needs to be addressed with more funds and more specific policies. We must bear in mind that most of the funds analyzed also pursue sectoral objectives that have not been the subject of this study, although these funds must be considered as a whole because they do not have separate items independently for the population. The approach and design of the CAP seeks to improve different variables, through different measures, but which in turn also have multiple objectives.

2. The determination of five differentiated zones, in terms of their economic behavior, suggests the possibility of acting in a differentiated way when implementing economic development policies that make it possible to take advantage of the local approach, from the bottom up, to develop specific needs. of each territory, which suggests a broader general framework, giving more scope for action to 
local agents depending on the needs of each area. The pre-existing administrative borders, based on non-economic criteria, can act as a brake on development actions.

3. The use of the direct subsidy method, predominant in the implementation of the CAP in Asturias for the period studied, could be improved with other methods of aid or public financing that perhaps provide better results from the point of view of entrepreneurship, development economic and population fixation in rural territories.

\section{Conclusions}

We have proposed an investigation to verify the hypothesis from which the Common Agrarian Policy starts, which is that investment or public spending contributes to stimulating rural sectors and territories significantly through the direct subsidy system, specifically and especially, among others variables, in the case of the population. We have focused the analysis on a significant territory, the Autonomous Community of the Principality of Asturias, with state powers to propose a specific policy, based on its own socio-economic characteristics and the administrative capacity transferred from the central government to execute and manage European funds and propose specific economic policy measures in this field of action.

From a methodological point of view, we have used spatial econometric techniques based on two independent but complementary approaches, one with crosssectional data and the other with panel data. In both approaches, negative and insignificant results are obtained for the contribution of public investment made in determining the population level. In the cross-sectional data approach, we have detected certain patterns of spatial dependence and possible spatial heterogeneity in the ESDA. For its study, we have carried out a confirmatory analysis that has indicated the use of spatial models that have incorporated spatial autocorrelation for the complete sample, specifically a spatial error model, and a non-spatial model, estimated by two-stage least squares for the sample without outliers, which excludes the most populated and urban councils of the considered territory. For the consideration of spatial heterogeneity, we have used switching regressions for five economically homogeneous zones and we have obtained for the two samples, with and without outliers, models that do include the existence of parametric instability.

We have proposed, to complement the study of cross-sectional data, a panel data approach that includes the time variable, given the multiannual nature of the funds under analysis. We have estimated several models, both with fixed and random effects, for different spatial models, in a process from the general to the particular, resulting in the spatial Durbin model with random individual effects that best explains. In none of the models are results obtained that allow us to consider that public funds from the CAP contribute positively to the improvement of population dynamics.

These results make us rethink the method of direct subsidy used, the need to redefine borders based on a territorial economic approach for the implementation of socio-economic and population development policies, as well as the need to distinguish between subsidy policy and economic policy of territorial development. 
Acknowledgements The authors thank to Ministerio de Ciencia e Innovación (project PID2019105986GB-C22) for partial support of this work.

Funding Ministerio de Ciencia e Innovación (project PID2019-105986GB-C22), partial support of this work. Open Access funding provided thanks to the CRUE-CSIC agreement with Springer Nature.

Availability of data and material The data used is public, comes from the official statistical information agencies, available almost entirely on its web pages, and the software used is mainly free and open source. In the article, the data sources and software used are clearly detailed and easily accessible to anyone interested. The datasets generated during and/or analysed during the current study are available from the corresponding author on reasonable request.

Code Availability The data used is public, comes from the official statistical information agencies, available almost entirely on its web pages, and the software used is mainly free and open source. In the article, the data sources and software used are clearly detailed and easily accessible to anyone interested. It is available from the corresponding author on reasonable request.

\section{Declarations}

Conflict of Interests The authors declare that they have no conflicts of interest.

Open Access This article is licensed under a Creative Commons Attribution 4.0 International License, which permits use, sharing, adaptation, distribution and reproduction in any medium or format, as long as you give appropriate credit to the original author(s) and the source, provide a link to the Creative Commons licence, and indicate if changes were made. The images or other third party material in this article are included in the article's Creative Commons licence, unless indicated otherwise in a credit line to the material. If material is not included in the article's Creative Commons licence and your intended use is not permitted by statutory regulation or exceeds the permitted use, you will need to obtain permission directly from the copyright holder. To view a copy of this licence, visit http://creativecommons.org/licenses/by/4.0/.

\section{References}

Alonso Cienfuegos, O. (2019). Have the funds of the second pillar of the cap 2007-2013 contributed to the creation of employment in rural Asturias? a spatial econometric approach with cross-sectional data. Journal of Quantitative Methods for Economics and Business Administration, 27, 235-258.

Alonso Cienfuegos, O., \& Otero Sánchez, A.I. (2019). A space-temporal analysis of the common agricultural policy in Asturias for the 2007-2013 programming period and its incidence in employment. Revista de Estudios Regionales, 116, 39-65.

Alonso-Villar, O., del Río, C., \& Toharia, L. (2009). UN Análisis espacial del desempleo por municipios. Revista de Economía Aplicada, 17(49), 47-80.

Álvarez, I., Barbero, J., \& Zofío, J (2017). A panel data toolbox for MATLAB. Journal of Statistical Software, 76(3), 1-27.

Álvarez-Díaz, M., D’Hombres, B., Ghisetti, C., Pontarollo, N., \& Dijkstra, L. (2018). The determinants of population growth: literature review and empirical analysis. JRC Working Papers in Economics and Finance, No 2018/10 European Commission Joint Research Centre. JRC, Ispra.

Álvarez Ramos, J. (2008a). La financiación de la política agraria común. Vida Rural. Suplemento, 265, 12-15. eUMEDIA SA, Ministerio de Agricultura, Pesca y Alimentación. Gobierno de España.

Álvarez Ramos, J. (2008b). La Gestión de los fondos de la pac en EspañA. Vida Rural. Suplemento, 265, 16-19. eUMEDIA SA, Ministerio de Agricultura, Pesca y Alimentación. Gobierno de España.

Anselin, L., \& Rey, S. (2014). MODern spatial econometrics in practice. Chicago: GeoDa Press LLC.

Becker, S., Egger, P., \& Von Ehrlich, M. (2010). Going nuts: the effect of eu structural funds on regional performance. Journal of Public Economics, 94(9-10), 578-590. 
Boarnet, M. (1998). Spillovers and locational effects of public infrastructure. Journal of Regional Science, $38,381-400$.

Cejudo García, D., \& Navarro Valverde, F. (2009). La inversión en los programas de desarrollo rural. SU reparto territorial en la provincia de granada. Anales de Geografía, 29(2), 37-64.

Chi, G., \& Zhu, J. (2008). Spatial regression models for demographic analysis. Population Research and Policy Review, 27, 17-42.

Costa da Silva, D., Elhorst, J., \& Silveira Neto, R. (2016). A spatial economic model and spatial econometric analysis of population dynamics in Brazilian MCAS. In Anais do XLII Encontro Nacional de Economia (Proceedings of the 42nd Brazilian Economics Meeting), ANPEC, 158.

Dall'Erba, S., \& Le Gallo, J. (2008). Regional convergence and the impact of European structural funds 1989-1999: A spatial econometric analysis. Papers in Regional Science, 82(2), 219-244.

De Dominicis, L. (2014). Inequality and growth in European regions: towards a place-based approach. Spatial Economic Analysis 9(2).

Elhorst, J. (2014). MATLAB software for spatial panels. International Regional Science Review, 37(3), 389-405.

Elhorst, J., Zandberg, E., \& de Haan, J. (2013). The impact of interaction effects among neighbouring countries on financial reform: A dynamic spatial panel data approach. Spatial Economic Analysis 8(3).

Getis, A., \& Ord, J. (1992). The analysis of spatial association by use of distance statistics. Geographical Analysis, 24, 189-206.

Gómez de Antonio, M. (2001). Evaluación del impacto del stock de capital público en el crecimiento de la renta per cápita de las provincias españolas (1981-1991) Mediante el empleo de técnicas econométricas de carácter espacial. Instituto de Estudios Fiscales. Colección Investigaciones (4/01).

Kelejian, H. H., \& Robinson, D. P. (1997). Infrastructure productivity estimation and its underlying econometric specifications: a sensitivity analysis. Papers in Regional Science, 76, 115-131.

Kelijian, H. H., \& Prucha, I. R. (2010). Specification and estimation of spatial autoregressive models with autoregressive and heteroskedastic disturbances. J Econometrics, 157, 53-67.

Kopp, A. (1995). Public investment-key to East German growth? In 51 Congress of international institute of public finance.

Le Gallo, J., Dall'Erba, S., \& Guillain, R. (2011). The local versus global dilemma of the effects of structural funds. Growth and Change 42(4).

Lesage, J., \& Fisher, M. (2008). Spatial growth regressions: model specification, estimation and interpretation. Spatial Economic Analysis 3(3).

Mohl, P., \& Hagen, T. (2010). DO structural funds promote regional growth? New evidence from various panel data approaches. Regional Science and Urban Economics, 40.

Mohl, P., \& Hagen, T. (2011). Do EU structural funds promote regional employment? Evidence from dynamic panel data models. Working Paper Series $n^{\circ} 1403$ European Central Bank. Eurosystem.

Moran, P. (1948). The interpretation of statistical maps. Journal of the Royal Statistical Society B, 10, 243-251.

Moreno, R., Artís, M., López-Baro, E., \& Surinach, J. (1997). Evidence on the complex link between infrastructure and regional growth. International Journal of Development Planning Literature, 12(12), 81-108.

Nieto Masot, A., \& Cárdenas Alonso, A. (2017). 25 Years of the leader initiative as European rural development policy: the case of extremadura (SW Spain). European Countrys, 2, 302-316.

Nieto Masot, A., \& Cárdenas Alonso, G. (2018). The rural development policy in extremadura (SW Spain): Spatial location analysis of leader projects. ISPRS International Journal of Geo-Information 7(2).

Nieto Masot, A., \& Gurría Gascon, J. (2008). Las políticas rurales Europeas Y SU impacto en extremadura. Boletín de la age, 48, 225-246.

Nieto Masot, A., Engelmo Moriche, A., \& Cárdenas Alonso, A (2017). Análisis espacial de la división comarcal en áreas rurales de baja densidad demográfica: el caso de extremadura. Papeles de Geografía, 63, 113-132.

Pellegrini, G., Terribile, F., Tarola, O., Muccigrosso, T., \& Busillo, F. (2013). Measuring the impact of the European regional policy on economic growth: A regression discontinuity approach. Papers in Regional Science 92(1).

Pieokowski, J., \& Berkowitz, P. (2015). Regional working paper 2015 econometric assessments of cohesion policy growth effects: how to make them more relevant for policy makers? Regional Working Paper 02/2015 European Comission. 
Rephann, T. J., \& Isserman, A. (1994). New highways as economic development tools: an evaluation using quasi-experimental matching methods. Regional Science and Urban Economics, 24, 723-751.

Rizov, M., Davidova, S., \& Bailey, A. (2018). Employment effects of cap payments in the UK non-farm economy. European Review of Agricultural Economics, 45(5), 723-748.

Romero, I., \& Fernández-Serrano, J. (2007). Un analisis de la heterogeneidad empresarial en la union Europea: implicaciones para la politica europea de fomento empresarial. Ekonomiaz, 66, 350-371.

Rural Development Program of Principality of Asturias (2013). Programa de Desarrollo Rural del Principado de Asturias 2007-2013. Gobierno del Principado de Asturias.

Schreiber, S. (2008). The HAUSMAN test statistic can be negative even asymptotically. Goethe University Frankfurt.

Sánchez Reyes, B. (2011). Evolución de la población de los municipios de extremadura: aplicaciones paramétricas y semiparamétricas. PhD thesis, Facultad de Ciencias Económicas y Empresariales. Universidad autónoma de Madrid.

Stata. (2005). Reference manual A-J, (pp. 441-448). Texas. Stata Press.

Vega, S. H., \& Elhorst, J. P. (2017). Regional labour force participation across the European Union: a timespace recursive modelling approach with endogenous regressors. Spatial Economic Analysis, $12(2-3), 138-160$.

Publisher's Note Springer Nature remains neutral with regard to jurisdictional claims in published maps and institutional affiliations. 